\title{
Reversal of ATP Inhibition of Phosphofructokinase by Nucleotides and Phosphate as a Possible Regulatory Mechanism of Sea Urchin Egg Glycolysis
}

\author{
Kouichi Asami, Akiko Fujiwara*, Ross L. Shoger* and Ikuo Yasumasu* \\ Division of Biology, National Institute of Radiological Sciences, Chiba 280 \\ * Department of Biology, School of Education, Waseda University, Totsuka, \\ Tokyo 160
}

\begin{abstract}
ABSTRAKT. Phosphofructokinase from eggs of the sea urchin Hemicentrotus pulcherrimus was inhibited with ATP at concentrations above $0.2 \mathrm{mM}$. AMP, ADP, adenosine 3'5'-cyclic phosphate (cyclic AMP) and orthophosphate relieved the enzyme from the ATP-inhibited state. Cyclic AMP was the most effective compound among these agents. Phosphofructokinase activity was measured in the presence of these positive and negative effectors. Concentrations of the effectors were chosen to match the intracellular concentrations of sea urchin eggs at selected post-fertilization periods. The results suggested that changes in phosphofructokinase activity after fertilization were due to changes in the concentrations of these effectors, especially cyclic AMP.
\end{abstract}

We have reported that three regulatory steps of glycolysis in sea urchin eggs, i.e., phosphorylase, phosphofructokinase and pyruvate kinase, are activated upon fertilization by different mechanisms (11). We have also demonstrated that the two regulatory enzymes phosphorylase (EC 2.4.1.1) and pyruvate kinase (EC 2.7.1.40) are actually activated upon fertilization $(2,9,13)$.

Activation of phosphofructokinase (EC 2.7.1.11) upon fertilization has also been suggested by an increase in the mass action ratio of the reaction catalyzed by the enzyme (11). Estimation of the enzyme activity in the egg homogenate, however, failed to show any activation at fertilization (13). Since the enzyme has been known to be under the control of various compounds (see ref. 8 for review) and to respond quickly against changes in the concentration of these compounds (3), it seems probable that the inevitable dilution of the intracellular effectors due to homogenization will bring about the inactivation of the enzyme. Therefore, it is important to investigate the activity of phosphofructokinase from sea urchin eggs in the presence of the effectors for elucidation of the regulatory mechanism of the enzyme.

The present paper describes the response of phosphofructokinase of sea urchin eggs to effectors, which have been known to regulate enzyme activity in other types of cells (8). ATP inhibited enzyme activity, and ATP-inhibition of the enzyme was reversed by adenosine $3^{\prime} 5^{\prime}$-cyclic phosphate (cAMP) and other adenine nucleotides

*Ross L. Shoger: A visiting NSF science faculty fellow; Present address, Department of Biology, Carleton College, Northfield, Minn., USA. 
or by orthophosphate. Furthermore, the activity measurement of phosphofructokinase under conditions where the concentrations of these effectors were simulated to their intracellular concentration $(11,12)$ indicated that the enzyme would be activated by changes in these effectors upon fertilization.

\section{MATERIALS AND METHODS}

Mature eggs of the sea urchin Hemicentrotus pulcherrimus were handled as described previously (11). Fertilized eggs were allowed to develop for $30 \mathrm{~min}$ after insemination at $21^{\circ} \mathrm{C}$ with gentle stirring. Eggs were washed with ice-cold $0.3 \mathrm{M}$ sucrose containing $0.15 \mathrm{M} \mathrm{KCl}$ and $0.15 \mathrm{M} \mathrm{NaCl}$ and homogenized with about 9 volumes of $0.5 \mathrm{M}$ sucorse containing $20 \mathrm{mM}$ 2-mercaptoethanol and $5 \mathrm{mM} \mathrm{MgCl}_{2}$.

The enzyme activity was measured as described previously (2). Two milliliters of the reaction mixture contained $40 \mathrm{mM}$ Tris $\mathrm{HCl} \mathrm{pH} \mathrm{7.4,} \mathrm{ATP} \mathrm{(the} \mathrm{concentration} \mathrm{is} \mathrm{specified} \mathrm{in} \mathrm{the} \mathrm{figure}$ legends), $0.075 \mathrm{mM} \mathrm{NADH}, 5 \mathrm{mM} \mathrm{MgCl}_{2}, 50 \mu \mathrm{g}$ aldolase, $10 \mu \mathrm{g}$ triosephosphate isomerase, $10 \mu \mathrm{g}$ glycerol 3-phosphate dehydrogenase, $5 \mathrm{mM}$ fructose 6-phosphate and $0.1 \mathrm{ml}$ homogenate. Fructose 6-phosphate was added last to start the enzyme reaction. Phosphofructokinase activity was followed as a decrease in absorbance at $340 \mathrm{~nm}$, measured on a photometer (Model Hitachi 124) and recorder eguipped with voltage compensating circuit. The minimum scale corresponded to absorbance of 0.001 . The velocity of decrease in absorbance at $340 \mathrm{~nm}$, caused with oxidation of NADH is correlated to that of fructose bisphosphateproduction by the enzyme. The compounds which were tested as effectors were added previously to the reaction mixture. When cAMP was used as an effector, $10 \mathrm{mM}$ theophylline was added to the reaction mixture, so as to prevent cAMP from breakdown by cyclicnucleotide phosphodiesterase in the egg homogenates (cf. Fig. 3b). The enzyme activity was expressed as nmoles fructose bisphosphate produced per min per $\mathrm{mg}$ protein. Protein was measured with the procedure of Lowry et al. (13).

Fructose 6-phosphate, NADH, aldolase, triosephosphate isomerase and glycerol 3-phosphate dehydrogenase were the products of Boeringer Mannheim Co., West Germany.

\section{RESULTS}

Fig. 1 shows the effect of $\mathrm{pH}$ on the activity of phosphofructokinase from sea urchin eggs. The $\mathrm{pH}$-activity curve of phosphofructokinase from fertilized eggs was found to be very similar to unfertilized eggs and showed a rather broad peak with a maximum point at $\mathrm{pH} 7.4$.

When phosphofructokinase activity was measured in the presence of varying concentrations of ATP, the activity was enhanced with increasing concentrations of ATP up to $0.1 \mathrm{mM}$, but decreased with a further increase of ATP concentration (Fig. 2). The ATP concentration which exhibited a half maximal inhibition was 0.27 and $0.37 \mathrm{mM}$ for unfertilized and fertilized eggs, respectively. However, the concentrationactivity relationship was very similar for unfertilized and fertilized eggs.

There was no substantial difference in the activity between unfertilized and fertilized eggs, although previous experiments predicted that the enzyme would be activated upon fertilization with a lag time of about $10 \mathrm{~min}$ after insemination (11). The discrepancy between the results observed here and previous studies was caused by the quick response of the enzyme against changes in effector concentrations (Fig. 3). When cAMP which is known to activate phosphofructokinase activity of other sources 


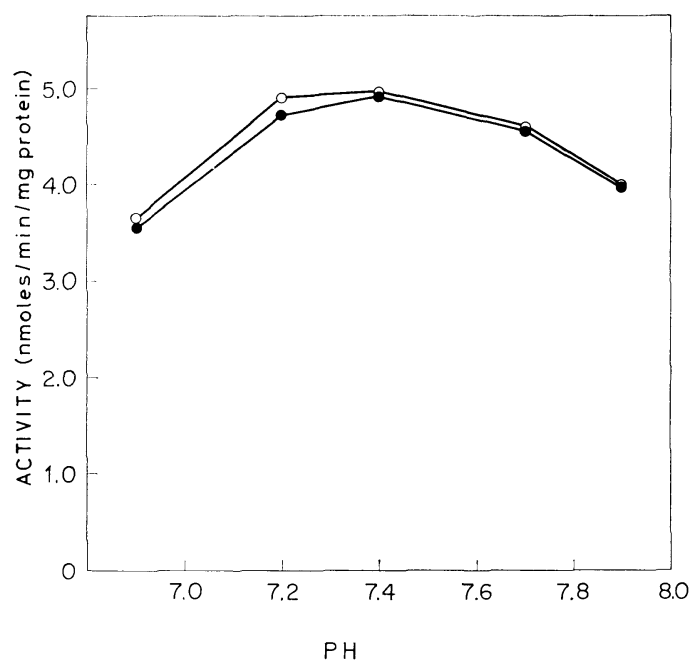

Fig. 1. Activity-pH relationship of Hemicentrotus phosphofructokinase. Concentration of Tris was $40 \mathrm{mM}$, and maleic acid or $\mathrm{HCl}$ was added to Tris solution to obtain the desired $\mathrm{pH}$. Concentration of ATP was $0.1 \mathrm{mM}$ and that of fructose 6-phosphate was $2.5 \mathrm{mM}$. $\bigcirc$, Unfertilized eggs; fertilized eggs.

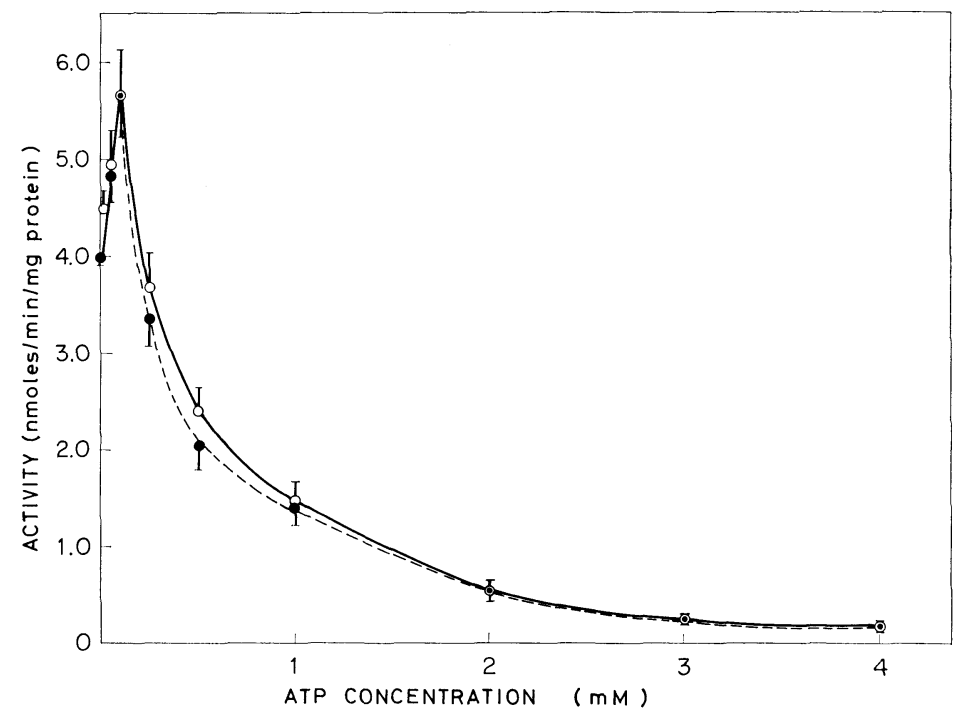

Fig. 2. Effect of varying concentrations of ATP on phosphofructokinase activity. Each point represents the mean of five separate experiments with SEM as a vertical bar. O, Unfertilized eggs; fertilized eggs.

was added to the reaction medium during measurement, immediate activation was observed (Fig. 3a). Addition of cyclicphosphate phosphodiesterase to the medium caused a gradual decrease in activity very similar to the decrease of authentic cAMP, as shown in Fig. 3b. Further addition of cAMP after addition of theophylline to 

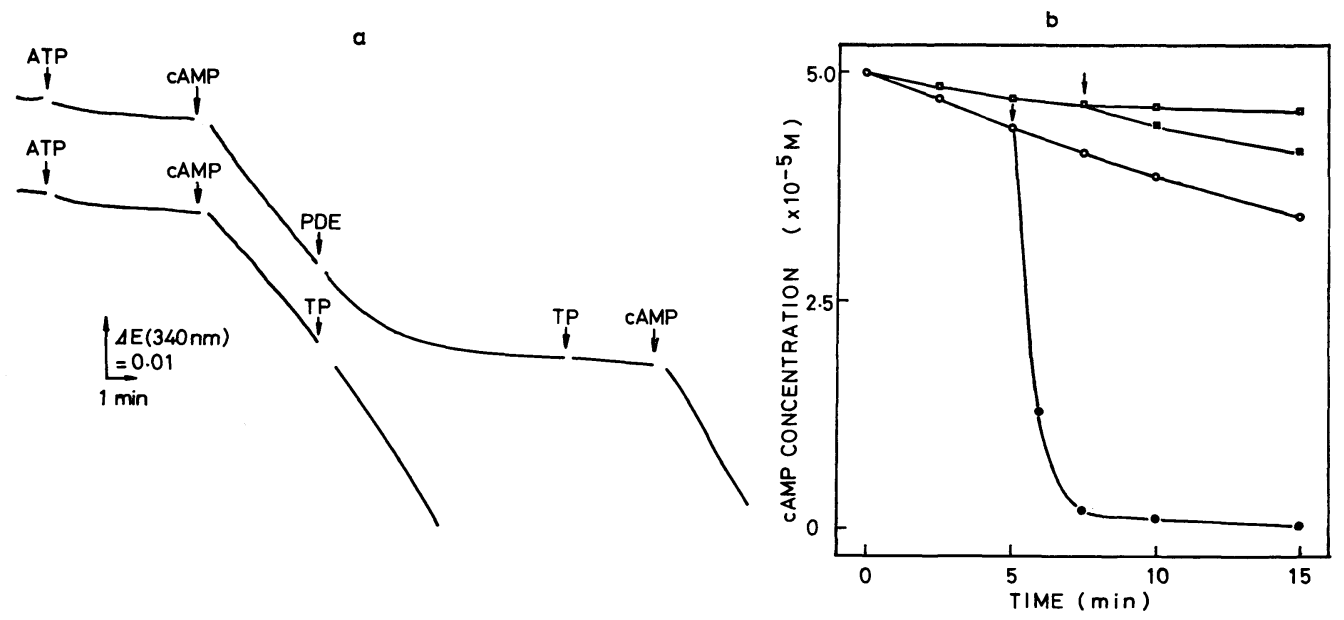

Fig. 3a. Activation of phosphofructokinase with cAMP. To the reaction medium described under Materials and Methods, the indicated compounds were added: $3 \mathrm{mM} \mathrm{ATP,} 50 \mu \mathrm{M} \mathrm{cAMP,} 20 \mu \mathrm{g}$ PDE (phosphodiesterase) and $1 \mathrm{mM}$ TP (theophylline). Homogenates from unfertilized eggs were used.

Fig. $3 b$. Breakdown of cAMP by phosphodiesterase. The same reaction medium used in Fig. $3 a$ was used except that the fructose bisphosphate consuming system was omitted. At time 0, cAMP was added at room temperature $\left(21.5^{\circ} \mathrm{C}\right)$, and at the indicated times, $0.1 \mathrm{ml}$ of reaction mixture was withdrawn and put into $1 \mathrm{ml}$ of water, incubated in advance at $95^{\circ} \mathrm{C}$. After $15 \mathrm{~min}$, the heated preparation was filtered through a millipore filter. cAMP content of the filtrate was determined enzymatically (12). Incubation was carried out without $(\bigcirc)$ or with ( $\square$ ) theophylline, and PDE was added at the arrows (०ם).

inhibit phosphodiesterase caused reactivation of the enzyme. Hence, the enzyme can respond quickly against changes of effector concentration.

Since the intracellular concentration of ATP in fertilized as well as unfertilized eggs is calculated to be about $3 \mathrm{mM}$ (11), the enzyme must be inhibited considerably in both the unfertilized and fertilized eggs. Thus, other factors which will relieve the enzyme from the ATP-inhibited state must be involved in the activation mechanism upon fertilization. Therefore, the effect of various compounds which had been reported to relieve the enzyme from ATP inhibition $(3,4,8)$ was examined on the ATPinhibited enzyme.

Fig. 4 shows the reversal of ATP inhibition of phosphofructokinase by cAMP on both unfertilized and fertilized sea urchin eggs. cAMP activated the ATP-inhibited enzyme (1-4 mM ATP), while it did not show any effect on the enzyme activity in the presence of $0.1 \mathrm{mM}$ ATP. One $\mathrm{mM}$ cAMP was sufficient for almost complete reversal against inhibition with 1 to $3 \mathrm{mM}$ ATP, and a half maximal release of inhibition was attained with about $10 \mu \mathrm{M}$ cAMP (Fig. 4).

Similar experiments were carried out with the other known effectors of the enzyme, i.e., ADP, AMP and orthophosphate. All these effectors were able to reverse ATPinhibition. However, since they were less effective than cAMP, only the results obtained with the highest concentrations of the effectors are shown in Table 1. Levels of $0.1 \mathrm{mM}$ and $2 \mathrm{mM}$ ATP were used as experimental conditions for the non-inhibited and the inhibited state, and the enzyme activity was expressed as a percentage of the non-inhibited control (Table 1). Addition of any effector resulted in a reversal of 


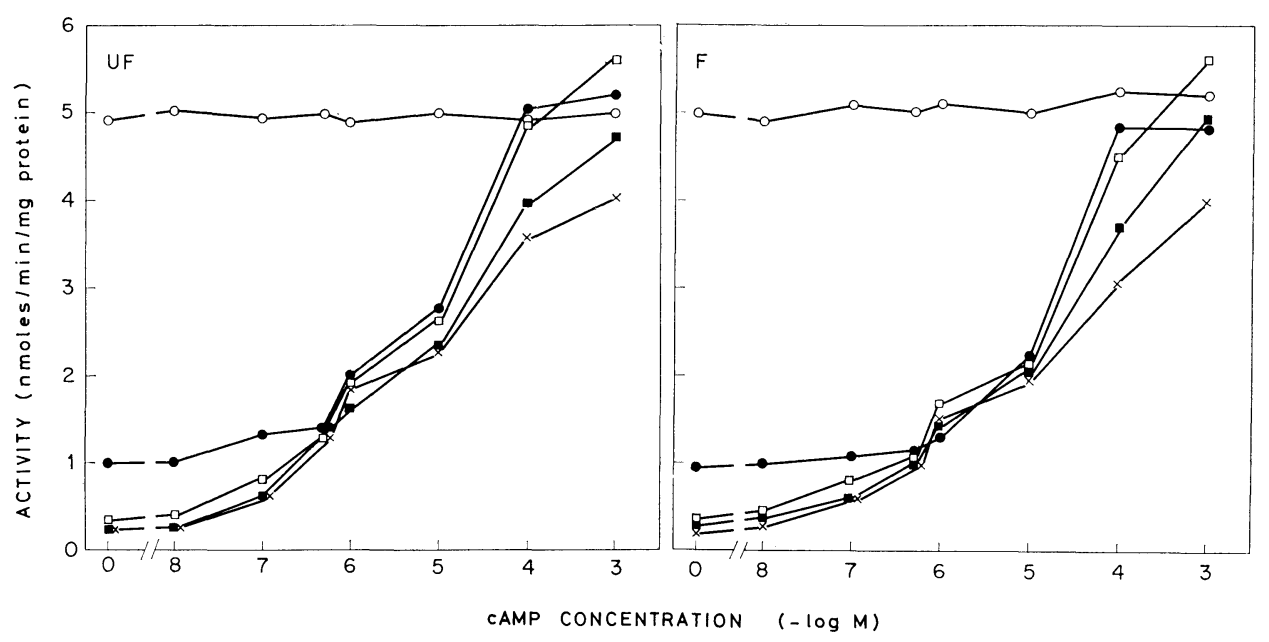

Fig. 4. Reversal by cAMP of ATP inhibition of phosphofructokinase. ATP concentration used for thea ssay was $\bigcirc, 0.1 \mathrm{mM} ; \bullet, 1 \mathrm{mM} ; \square, 2 \mathrm{mM} ; \mathbf{\square}, 3 \mathrm{mM}$; and $\times, 4 \mathrm{mM}$. UF, Unfertilized eggs; F, fertilized eggs.

TABLE 1. REVERSAL BY SEVERAL EFFECTORS OF PHOSHOFURUCTOKINASE INHIBITED BY ATP

\begin{tabular}{lcc}
\hline Effectors & Concn. (M) & Activity (\%) \\
\hline None & - & 7.4 \\
Phosphate & $10^{-1}$ & 35 \\
AMP & $10^{-3}$ & 31 \\
ADP & $10^{-3}$ & 16 \\
cAMP & $10^{-3}$ & 112 \\
\hline
\end{tabular}

ATP concentration of the assay mixture was 2 $\mathrm{mM}$ except for the non-inhibited control $(0.1$ $\mathrm{mM})$. The enzyme activity is expressed as a percentage of the non-inhibited control $(5.34 \pm$ $0.41 \mathrm{nmoles} / \mathrm{min} / \mathrm{mg}$ protein).

ATP-inhibition. But they were far less effective than cAMP.

The activation of the enzyme upon fertilization which has been suggested in the previous paper (11) is probably due to the change in the intracellular concentrations of these effectors, since the contents of these compounds in the eggs have been reported to change upon fertilization $(11,12)$. Therefore, phosphofructokinase activity of unfertilized eggs was measured in the presence of effectors. The concentrations were made so as to simulate those at selected post-fertilization periods. Their concentrations were estimated from our previous results summarized in Table 2.

Fig. 5 shows the activities of phosphofructokinase from unfertilized eggs under conditions where concentrations of the effectors were chosen to match the intracellular concentration at each post-fertilization time. The activity change of the complete system (Fig. 5a) seems to be very close to the activity change observed upon fertilization, which was estimated by measurement of the free energy change in the reaction catalyzed by the enzyme (cf. Fig. 3 of ref. 11). 
TABLE 2. INTRACELLULAR CONCENTRATIONS OF ADENINE NUCLEOTIDES AND ORTHOPHOSPHATE (Pi) AS A FUNCTION OF POST-FERTILIZATION TIME

\begin{tabular}{lllllll}
\hline \multirow{2}{*}{ Compounds } & \multicolumn{7}{l}{ Post-fertilization time (min) } & & & \\
\cline { 2 - 7 } & UF & 10 & 20 & 30 & 40 & 60 \\
\hline cAMP (BM) & 0.10 & 0.02 & 0.10 & 0.20 & 0.40 & 1.0 \\
ATP (mM) & 3.5 & 3.5 & 3.5 & 3.0 & 3.0 & 2.0 \\
ADP (mM) & 0.25 & 0.35 & 0.50 & 0.50 & 0.50 & 0.45 \\
AMP (mM) & 0.15 & 0.20 & 0.20 & 0.20 & 0.20 & 0.15 \\
Pi (mM) & 80 & 80 & 80 & 80 & 80 & 80 \\
\hline
\end{tabular}

Values were calculated from ref. 12 (cAMP) and Table 1 of ref. 11 and used for experiments shown in Fig. 5. UF, unfertilized eggs.

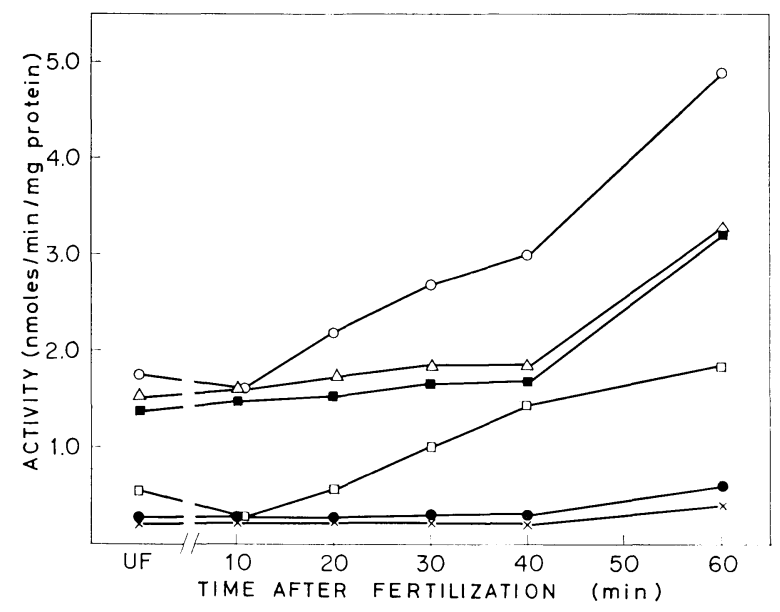

Fig. 5. Phosphofructokinase activity from unfertilized eggs measured in a simulated condition for changes in effector concentrations after fertilization. The enzyme activity of the unfertilized egg homogenate was assayed in the presence of various effectors; the concentrations were chosen so as to match the intracellular concentration at the corresponding time, as shown in Table 2. The enzyme activity was measured under various effector combinations: (a) ATP, ADP, AMP, Pi (orthophosphate) and cAMP (O); (b) ATP, ADP, AMP and Pi $(\triangle)$; (c) ATP, ADP and AMP (ם); (d) ATP and cAMP $(\square)$; (e) ATP and ADP (•); and (f) ATP alone $(\times)$. UF, Unfertilized eggs.

The enzyme activity was also measured with the addition of various combinations of effectors, as shown in Fig. 5, to determine the effector that mainly controls the activity change in eggs after fertilization. The enzyme activity in unfertilized eggs seems to be mainly controlled by AMP, since the AMP-containing system (Fig. 5a, $\mathrm{b}$ and $\mathrm{c}$ ) showed consistently higher activity than the system lacking AMP (Fig. 5d, e and f). However, cAMP is the most important factor controlling the activity change after fertilization, since systems containing only cAMP and ATP (Fig. 5d) showed activity changes similar to the complete system.

\section{DISCUSSION}

Inhibitory action of ATP on phosphofructokinase has been well established $(3,8)$, and sensitivity differences to ATP are observed among the isoenzymes of rats $(4,10)$. 
At neutral $\mathrm{pH}$, the muscle enzyme is rather resistant to ATP, while the thymocyte enzyme is sensitive (10). Since the endogenous effectors in the eggs are diluted approximately 200 -folds in the assay mixture, the contribution of the endogenous effectors to the enzyme activity is negligible. Sea urchin egg phosphofructokinase has a sensitivity analogous to the rat thymocyte enzyme. However, the egg phosphofructokinase is relieved from the ATP-inhibited state with a lower concentration of cAMP than thymocyte enzyme. To further clarify the molecular property of the sea urchin enzyme, experiments on purified preparation will be necessary.

Activation of phosphofructokinase upon fertilization was assumed in the previous paper based on the increase in mass action ratio of the glycolytic step catalyzed by the enzyme (11). Increased enzyme activity, however, was not detected in the homogenates of fertilized eggs (13). Since the enzyme responded quickly to changes in the concentration of effectors, the active form of the enzyme in fertilized eggs, which was maintained active by intracellular effectors, returned instantly to the inactive form due to the inevitable dilution caused by homogenization of the eggs. Since the effectors examined were able to stimulate the enzyme in the range of their intracellular concentrations, it is probable that the enzyme in the eggs is maintained in an active form with these effectors. Moreover, as shown in the simulation experiments (Fig. 5), the activation of the enzyme upon fertilization is caused by the increase and/or decrease in the concentrations of the effectors. Examination of enzyme activity under various combinations of effectors revealed that the main effector responsible for the activation of enzyme upon fertilization is cAMP and that the activity in the unfertilized eggs is controlled by AMP. This conclusion may not conflict with the assumption in the previous paper that the decline of phosphate potential after fertilization might stimulate the activity of phosphofructokinase in sea urchin eggs (11). But the decline of phosphate potential may not be the main reason for phosphofructokinase activation upon fertilization.

From the data presented so far, we may postulate a sequence of events triggered by fertilization and resulting in activation of glycolysis. At fertilization, $\mathrm{Ca}$ ions penetrate into eggs (7) resulting in increased free $\mathrm{Ca}$ ions in eggs $(5,6)$. Adenylate cyclase is activated with a mechanism unknown at present and cAMP concentration starts increasing with a lag time of about $10 \mathrm{~min}(1,12)$. Then, the combined action of $\mathrm{Ca}^{2+}$ and cAMP activates phosphorylase (9) and pyruvate kinase (2). A further increase in cAMP causes an activation of phosphofructokinase, as described earlier. The resulting increase in fructose 1,6-bis-phosphate causes further activation of pyruvate kinase (2). Thus, the glycolytic system in sea urchin eggs enters into an active or reactive state responsive to changes in the energy utilizing systems.

\section{REFERENCES}

1. Castenda, M., and A. Tyler. Adenyl cyclase in plasma membrane preparation of sea urchin eggs and its increase in activity after fertilization. Biochem. Biophys. Res. Commun. 33, 782787, 1968

2. Fujiwara, A., K. Asami, R.L. Shoger, and I. Yasumasu. Factors affecting the activity and the distribution of pyruvate kinase in sea urchin eggs. Exp. Cell Res. submitted for publication.

3. Hess, B., A. BoIteux, and J. KrüGer. Cooperation of glycolytic enzymes. Adv. Enzyme Regulation. 7, 149-167, 1969

4. KemP, P.G. Rabbit liver phosphofructokinase. Comparison of some properties with those of muscle phosphofructokinase. J. Biol. Chem. 246, 245-252, 1971 
5. Mazia, D. The release of calcium in Arbacia eggs on fertilization. J. Cell. Comp. Physiol. 10, 291-304, 1937

6. Nakamura, M., and I. Yasumasu. Mechanism for increase in intracellular concentration of free calcium in fertilized sea urchin egg. A method for estimating intracellular concentration of free calcium.J. Gen. Physiol. 63, 374-388, 1974

7. Nakazawa, T., K. Asami, R.L. Shoger, A. Fujiwara, and I. Yasumasu. $\mathrm{Ca}^{2+}$ uptake, $\mathrm{H}^{+}$ejection and respiration in sea urchin eggs on fertilization. Exp. Cell Res. 63, 143-146, 1970

8. Rose, I.A., and Z.B. Rose. Glycolysis: Regulation and mechanisms of the enzymes. In Comprehensive Biochemistry. ed. Florkin, M., and E.H. STOTz, Elsevier, Amsterdam, vol. 17, 93161, 1969

9. Shoger, R.L., K. Asami, I. Yasumasu, and A. Fujiwara. Activation of phosphorylase in sea urchin eggs by $\mathrm{Ca}^{2+}$ and cyclic $3^{\prime} 5^{\prime}$-AMP. A possible mechanism of the regulation of its activity at fertilization. Exp. Cell Res. 82, 375-382, 1973

10. Yamada, T., and H. Ohyama. Rat thymocyte phosphofructokinase: some kinetic properites compared with those of muscle phosphofructokinase. Biochim. Biophys. Acta 284, 101—109, 1972

11. Yasumasu, I., K. Asami, R.L. Shoger, and A. Fujiwara. Glycolysis of sea urchin eggs. Ratelimiting steps and activation at fertilization. Exp. Cell Res. 80, 361-371, 1973

12. Yasumasu, I., A. Fujiwara, and K. Ishida. Periodic change in the content of adenosine $3^{\prime} 5^{\prime}$ cyclic monophosphate with close relation to the cycle of cleavage in the sea urchin egg. Biochem. Biophys. Res. Commun. 54, 628-632, 1973

13. Yasumasu, I., A. Fujiwara, R.L. Shoger, and K. Asami. Distribution of some enzymes concerning carbohydrate metabolism in sea urchin eggs. Exp. Cell Res. 92, 444-450, 1975

(Received for publication, June 30, 1975) 